\title{
Potential Activity of Some Essential Oils and Human Amniotic Membrane against Malassezia furfur and Staphylococcus aureus Isolated from Pityriasis Versicolor Patients
}

\author{
Seham Y. El-Tablawy(1), Nashwa K. Radwan ${ }^{(2)}$ and Eman Araby(3)\# \\ ${ }^{(1)}$ Drug Radiation Research Department; ${ }^{(2)}$ Health Research Department and \\ (3) Radiation Microbiology Department, National Centre for Radiation Research and \\ Technology (NCRRT), Egyptian Atomic Energy Authority (EAEA), P.O. Box 29, Nasr \\ City, Cairo, Egypt.
}

\begin{abstract}
COME Malassezial and bacterial species may act as pathogens when exposed to certain changes in the skin microclimate causing many diseases as Pityriasis versicolor (PV). Currently available drugs have various limitations, therefore attention should be drawn towards different natural products being widely popular for antimicrobial properties. The antimicrobial potentiality of five essential oils (EOs) as well as irradiated and non-irradiated human amniotic membrane (HAM) against the growth of Malassezia furfur and Staphylococcus aureus isolated from PV patients was evaluated. Combination treatment between the most potent tested antimicrobial agents was conducted by the checkerboard technique. Results revealed that the highest antimicrobial activity was exhibited by tea tree oil (TTO) and non-irradiated HAM layered and supernatant (HAM L/S) against all the tested strains. Combination of TTO with HAMS resulted in a strong synergistic activity, significantly reduced the MICs of both agents. Moreover, the mode of action of combination treatment on cell membrane of the tested pathogens was confirmed by marked release of cellular materials that absorb at $260 \mathrm{~nm}$, and efflux of potassium ion. In addition, the scanning electron microscopic analysis confirmed the inhibitory effect of combination of TTO with HAMS by revealing significant morphological alterations and rupture of the cell membranes of the tested strains. These findings suggest that combination holds a broad-spectrum antimicrobial efficacy, confirming its influence on the membrane integrity and morphological characteristics of tested pathogens, which provides promising information on the potential use of TTO with HAMS for treatment of PV patients.
\end{abstract}

Keywords: Antimicrobial activity, Human amniotic membrane, Essential oils, Gamma radiation, Pityriasis versicolor.

\section{Introduction}

Pityraisis versicolor (PV) which is also called Tinea versicolor (TV) is one of the most common chronic skin diseases in tropical and subtropical areas of the world. People who live in tropical areas may have PV year-round. The first sign of $\mathrm{PV}$ is often lighter spots on the skin with variable colour; white, pink, salmon, tan or brown, the spots can be dry and scaly (Framil et al., 2010 and Park et al., 2012). Malassezia species are yeasts that comprise part of the micro flora of human skin, especially; they are abundant in regions supplied with sebaceous glands because of their lipid requirement for growth. Certain environmental, genetic, and immunological factors can predispose to the conversion of the yeast into the pathogenic state and contribute to the development of PV. The most important predisposing factors are heat (summer months), humidity, hyperhidrosis, malnutrition, pregnancy, oral contraceptives, stress, application of oily preparations and creams, and treatment with corticosteroids (Rios-Yuil, 2016).

Malassezia furfur is one of the main causative agents of PV. All traditional drugs have certain limitations, either due to poor clinical efficacy or the compliance issues. Furthermore, these drugs are unable to prevent recurrence, which is the most common problem. Such complications have prompted the search for novel and effective antifungal agents of a natural origin (Pooja et al., 
2013). Staphylococcus aureus (S. aureus) is one of the important bacterial pathogens and could cause skin infections, endocarditis, septicemia, meningitis, septic arthritis, toxic shock syndrome, medical device-related infections (Kurlenda \& Grinhole, 2012). Due to microbial resistance towards the available antimicrobial agents and consequently limited efficacy of these medications, many patients have turned to alternative therapies including essential oils (EOs). The antimicrobial properties of EOs are mainly due to their volatile components, including terpenoids and phenolic compounds. The mechanism of EOs to inactivate microorganisms relies on their interaction with the microbial membrane. EOs phenolic compounds are known to penetrate through the microbial membrane, cause the leakage of ions and cytoplasmatic content, and thus lead to cellular breakdown (Guerra-Rosas et al., 2017).

Human amniotic membrane (HAM) is the inner most living of the human placenta. It has various growth factors, proteins, defensins \& stem cells; it is considered a promising material in many applications (Feng \& Yu, 2014). In order to avoid the transmission of any diseases, HAM should be perfectly sterile. Sterility by ionizing radiation is rapid and effective in killing all live microorganisms.

The purpose of the present study is to evaluate the potential activity of certain essential oils \& HAM (irradiated and non- irradiated) against the selected isolates from PV patients. In addition, the study aims to investigate the synergistic effects of the most potent one combined with HAM, thereby throwing light on the potential role of EOs in increasing the effectiveness of HAM.

\section{Materials and Methods}

\section{Patients and samples collection}

The study concerned $48 \mathrm{PV}$ patients in the dermatology clinic of (NCRRT) (22 females and 26 males; 25-56 years old). After obtaining informed consent, samples were collected by swab method from different areas of the body. All the patients were diagnosed clinically by two independent dermatologists evaluating the PV area. All procedures performed in this study involving human participants were in accordance with the Helsinki (2013) declaration.

A sterile cotton swab soaked with sterile saline was used to rub against the skin surface, with continuous rotation of the swab for at least $15 \mathrm{sec}$, and immediately streaked evenly onto Tryptone glucose yeast extract agar (TGY) medium and Sabauroud Glucose Agar (SGA) supplemented with olive oil and modified Leeming supplemented with cycloheximide $(0.5 \%)$ and chloramphenicol $(0.05 \%)$ as recommended by Sugita et al. (2003), then incubated at $32^{\circ} \mathrm{C}$ for $18 \mathrm{~h}$ and 14 days for bacterial and fungal isolates, respectively. After one week of incubation, physiological characters were examined by cell morphology, Gram staining and light microscope.

For isolation of Malassezia spp., isolates have undergone differentiation cultures including Dixon's agar (DA), modified Dixon's agar (mDA), Esculin agar media and growth in the presence of Tween $-20,-40,-60,-80$.

\section{Tween assimilation test}

The ability to utilise individual Tween compounds (Tween-20, -40, -60 and -80) was tested according to Gupta et al. (2001). Briefly, sterile Sabouraud's agar $(16 \mathrm{ml})$ was melted and allowed to cool to approximately $50^{\circ} \mathrm{C}$. Malassezia yeast suspensions (about $10^{5} \mathrm{cfu} . \mathrm{ml}^{-1}$ ) were mixed with Sabouraud's agar, and the mixtures were plated. Five holes were made in the agar with a $10 \mathrm{~mm}$ diameter punch and filled with $5 \mu 1$ of Tween- 20, $-40,-60$ and -80 . The plates were incubated for one week at $32^{\circ} \mathrm{C}$. Utilisation of Tween was assessed by the degree of growth and/or reaction (precipitation) of the lipophilic yeast around individual wells.

\section{Splitting of esculin}

According to the method described by Mayser et al. (1997), the $\beta$-glucosidase activity of different Malassezia species was assayed. Briefly, the loop of fresh yeast was deeply inoculated in the esculin agar (Merck, Germany) tube and incubated for 5 days at $32^{\circ} \mathrm{C}$. The splitting of esculin is indicated by darkening of the medium. This test was used to distinguish $M$. furfur, $M$. slooffiae and $M$. sympodialis from other Malassezia species.

\section{Pigmentation}

The modified Dixon medium (mDixon) prepared by replacing peptone with equal amounts $(0.6 \%)$ of L-tryptophan was used for cultivation and pigment induction by all fungal isolates. This medium consisted of $3.6 \%$ malt extract, $2.0 \%$ desiccated Ox-bile, 1.0\% Tween 40, 0.2\% glycerol, $0.2 \%$ oleic acid, $0.5 \%$ cycloheximide, and $1.2 \%$ 
agar. After sterilisation and cooling to $50^{\circ} \mathrm{C}$, then filtered sterilized $0.05 \%$ chloramphenicol and $0.6 \%$ L-tryptophan were added to other ingredients. Formation of specific pigment was evaluated macroscopically after $1-7$ days incubation at $32^{\circ} \mathrm{C}$ (Ghahfarokhi \& Abyaneh, 2004).

\section{Isolation of S. aureus strains}

For isolation of S.aureus, all Gram positive cocci isolates have been cultured on selective media including; Mannitol salt agarand Barid-paker agar media according to Holt et al. (1993).

Some biochemical tests were used to confirm $S$. aureus such as hemolysis of blood agar, coagulase test and catalase test.

\section{Hemolysis of blood agar}

All the isolates were tested for haemolysis after overnight incubation at $35^{\circ} \mathrm{C}$ on sheep blood agar prepared as follows: $15 \mathrm{ml}$ of $5 \%$ sheep blood in Trypticase soy agar as overlay on $10 \mathrm{ml}$ of blood agar base. Hemolysis was recorded as $\alpha$-haemolysis, $\beta$-hemolysis, double hemolysis ( $\alpha$ and $\beta$ ), and negative (no hemolysis) (Boerlin et al., 2003).

\section{Coagulase test}

Plasma was diluted to 10 times in physiological saline and $0.5 \mathrm{ml}$ of the diluted plasma was placed in a small tube. A colony of the test organism was emulsified in the diluted plasma. The tubes were incubated at $35^{\circ} \mathrm{C}$ and checked every $30 \mathrm{~min}$ for up to $4 \mathrm{~h}$ for clot formation (Boerlin et al., 2003).

\section{Catalase reaction}

The presence of catalase was determined by adding a drop of hydrogen peroxide ( $3 \%$ solution) to the growing colonies, the production of gas bubbles was considered a positive reaction (Isobe et al., 2006).

\section{Antimicrobial agents}

\section{Essential oils}

Five essential oils (EOs) (Tea tree,clove, rosemary, eucalypts and cinnamon) were purchased from Ayurveda for Healthy Foods ${ }^{\circledR}$, Nasr City, Cairo, Egypt. Stock solutions of 50\% from EOs were prepared in dimethylsulfoxide (DMSO, Sigma-Aldrich; v/v).

\section{Human amniotic membrane}

Human placenta was obtained from blood borne viruses free-mothers at $\mathrm{Al}$ Demerdash
Maternal Hospital, Ain Shams University, Cairo, Egypt, after cesarean delivery. The placenta was soaked in chilled isotonic saline solution and immediately delivered into ice box to Amniotic Tissue Laboratory at NCRRT, (EAEA), Cairo, Egypt. Bio-safety precautions were considered for amniotic tissue handling and transportation processes as a potential hazard materials in accordance to guidelines published by Haidaris \& Brownlow (2001).

HAM preparation: HAM was separated from placental tissues by blunt dissection under current of tap water and washed several times in sterile phosphate buffered saline under aseptic conditions until obtaining cleared HAM. All media and buffers used below were purchased from Lonza (UK). The clear HAM was disinfected by soaking it into $250 \mathrm{ml}$ Hanks balanced salt solution (HBSS) contained antibiotic/antimycotic mix into sterilised glass bottle and incubated overnight at $37^{\circ} \mathrm{C}$. For obtaining irradiated HAM, fresh washed transparent HAM was layered on cotton dressing gauzeas (a supporting material), frozen and dried prior to irradiation treatment.(Nemr et al., 2016). The irradiation at dose $25 \mathrm{kGy}$ was conducted using Cobalt $60\left({ }^{60} \mathrm{Co}\right)$ Gamma Cell, product of Canada Co. Ltd. located at NCRRT, Cairo, Egypt. The dose rate at the time of this experiment was $1.85 \mathrm{kGy} / \mathrm{h}$.

HAM tissue culturing: Freshly prepared HAM and IHAM were cultivated in $5 \mathrm{ml}$ Minimal Essential Medium (MEM) supplemented with $10 \%$ Fetal Bovine Serum (FBS) in a sterile glass petri dish cultures incubated at $37^{\circ} \mathrm{C}$ in humidified $\mathrm{CO}_{2}$ incubator. $\mathrm{HAM}$ cultures were maintained every 3-5 days by adding $5 \mathrm{ml}$ fresh medium free from antibiotic/antimycotic, at least two passages were carried out (Nemr et al., 2016).

Evaluation of antimicrobial potentiality of the tested essential oils (EOs)

Antimicrobial activity of the tested oils against Malassezia furfurand S. aureus was evaluated by disc diffusion assay. Whatman No.1 filter paper discs, $6.0 \mathrm{~mm}$ in diameter, sterilised in dry heat at $80^{\circ} \mathrm{C}$ in an oven for $1 \mathrm{~h}$ were used to determine antimicrobial activity. Sabouraud dextrose agar and Muller Hinton agar media were prepared for M. furfur and S. aureus, respectively. After sterilisation, it was poured into sterilised Petri plates and allowed to solidify. Using a sterile cotton swab, culture was swabbed on the surface 
of medium plates. The discs were loaded with $20 \mu 1$ from each oil and aseptically placed over plates containing medium(the tested oils were dissolved using DMSO). Along with the five tested oils, discs saturated with nystatin as antifungal and gentamycin as antibacterial taken as standards. Three replicates were maintained for each sample. The plates were incubated at $32^{\circ} \mathrm{C}$ and the zone of inhibition was observed after 4 days and $18 \mathrm{~h}$. for $M$. furfur and $S$. aureus, respectively. Control was maintained with filter paper discs dipped in DMSO.

\section{Antimicrobial potentiality of HAM and IHAM}

Antimicrobial activity of HAM and IHAM was tested in two ways, namely by treating microbial culture with HAM itself layered $(5 \mathrm{~cm} \times 5 \mathrm{~cm})$ on the surface of microbial solid culture, or by loading $25 \mu \mathrm{l}$ of aspirated waste medium, collected after 3-5 days of HAM culture medium replacement (HAMS), into wells punched into agar solid medium.

\section{Determination of minimal inhibitory concentrations (MICs), minimumfungicidal/ bactericidal concentration ( $M F C, M B C$ )}

MICs values were determined by the microtiter broth method according to Clinical and Laboratory Standards Institute guidelines (CLSI, 2008) in sterile flat-bottom 96-well polystyrene plates. Serial dilution techniques were used to determine the MICs of TTO which ranged from 5 to $250 \mu \mathrm{l} / \mathrm{ml}$ medium and HAMS ranged from 2.5 to $125 \mu \mathrm{l} / \mathrm{ml}$ medium. For combination treatment, the concentrations were in the range $(2.5-50 \mu \mathrm{l} /$ $\mathrm{ml}$ medium). A final concentration $\left(3 \times 10^{7} \mathrm{cfu} / \mathrm{ml}\right)$ of tested organisms was added to each dilution. The plates were incubated at $32^{\circ} \mathrm{C}$ for 4 days and $18 \mathrm{~h}$ for $M$. furfur and $S$. aureus, respectively. MIC was defined as the lowest concentration of antimicrobial agent that inhibited the microbial growth, as indicated by the absence of turbidity. Each test included two growth controls consisting of the medium with the solvent (DEMSO) and the medium with microbial suspension. After MIC determination of the tested antimicrobial agents, aliquots of $50 \mu \mathrm{l}$ from all wells, in which no visible microbial growth was observed, were seeded in media plates not supplemented with any antimicrobial agents and were incubated at $32^{\circ} \mathrm{C}$ for $24 \mathrm{~h}$ and 4 days for $S$. aureus and $M$. furfur, respectively. The MFC and MBC endpoints are defined as the lowest concentration of antimicrobial agent that kills $100 \%$ of the initial microbial population. All assays were carried out in triplicate, and at least on three different occasions.

\section{Synergy testing}

The checkerboard method, which is commonly used for measurement of interactive inhibition, was used for determination of synergy between the antibiotics and natural antimicrobials. The checkerboard method is often combined with calculation of a fractional inhibitory concentration (FIC) index to test the antimicrobial potencies of drugs in medical laboratories. The FIC was derived from the lowest concentration of TTO and HAMS combination permitting no visible growth of the test organisms on the plates. A FIC value for each agent was calculated using the formula:

FIC $($ TTO $)=$ MIC of TTO in combination/ MIC of TTO alone.

FIC $($ HAMS $)=$ MIC of HAMS in combination/ MIC HAMS alone.

FIC index $=$ FIC of TTO + FIC of HAMS.

Combinations were classified as synergistic, if the FIC indices were $\leq 0.5$, additive if the FIC indices were $>0.5$ and $\leq 1.0$, indifferent if FIC $>1.0$ and $\leq 2.0$, and antagonistic if FIC $>2.0$ (Yadav et al., 2013). All assays were carried out in triplicate.

\section{Release of intracellular material}

Cells of $M$. furfur 25 about $\left(1 \times 10^{6}\right)$ and $S$. aureus 3 about $\left(1 \times 10^{5}\right)$ were grown in Sabouraud dextrose broth and peptone water $(0.1 / 100 \mathrm{ml})$, for 4 days and $18 \mathrm{~h}$, respectively. They were collected, washed three times and resuspended to in PBS, $\mathrm{pH}$ 7.4. Measurements of the release of material absorbing at $260 \mathrm{~nm}$ from the tested strains were conducted using $2 \mathrm{ml}$ aliquots of the microbial inocula after the addition of MIC of combination (TTO \& HAMS). At different time intervals $(0,10,30,60$ and $120 \mathrm{~min})$, microbial cells were centrifuged at $3,000 \mathrm{rpm}$ for $10 \mathrm{~min}$ and the obtained supernatants were measured spectrophotometrically using JASCO V 560 UV/ VIS spectrophotometer at $260 \mathrm{~nm}$ to detect the microbial cell damage. Control flasks without antimicrobial agents were tested similarly. The experiment was performed in triplicate (Bajpai et al., 2014). 
Potassium ions efflux assay

The concentration of free potassium ions in microbial suspension of $M$. furfur 25 about $\left(1 \times 10^{6}\right)$ and $S$. aureus 3 about $\left(1 \times 10^{5}\right)$ was measured after exposure to MIC of combination of (TTO \& HAMS) in sterile Sabouraud dextrose broth and peptone water $(0.1 / 100 \mathrm{ml})$ for 0,30 , 60 , and $120 \mathrm{~min}$. At each pre-established interval, the extracellular potassium concentration was measured by photometer (Alfa Wassermann Starlyte 111, Na+, K+, Cl- analyzer). Control flasks without any treatment were tested similarly. Results were expressed as amount of extracellular free potassium $(\mathrm{mmol} / \mathrm{l})$ in the growth media in each interval of incubation (Bajpai et al., 2014). All experiments were conducted in triplicate.

\section{Scanning electron microscopic analysis}

Scanning electron microscopic (SEM) observations were used to determine the effect of combination of (TTO \& HAMS) at MICon morphology of the tested organisms. Control samples were prepared without the (TTO \& HAMS), after incubation at $32^{\circ} \mathrm{C}$ for $18 \mathrm{~h}$., cells were harvested by centrifugation for $10 \mathrm{~min}$. at $4,500 \mathrm{rpm} /$ min and washed twice with $0.9 \%$ saline solution, and then were resuspended in water containing $2.5 \%$ glutaraldehyde and kept at $-4^{\circ} \mathrm{C}$ for $10 \mathrm{~h}$ to fix the cells. After centrifugation, the cells were further dehydrated in water-alcohol solutions at various alcohol concentrations $(30,50,70,80,90$ and $100 \%$ ) for $10 \mathrm{~min}$. Finally, the samples were fixed and then sputter coated with gold under vacuum and were examined in the JEOL- JSM -5400 scanning electron microscope (Japan).

\section{Statistical analysis}

Means and standard deviation of the samples were statistically calculated. Each treatment was carried out with three replicates. Analysis of variance using one-way ANOVA followed by Duncan's test was performed to test the significance of differences between means obtained among the treatments at the 5\% level of significance. All statistical analysis was performed using SPSS version 16.0.

\section{Results}

Out of 48 patients affected by PV (based on clinical appearance, itching and other investigations) as previously mentioned, 40 cases $(83.33 \%)$ were positive for microbial growth. The results represented in Table 1 and Fig. 1 show that among these positive cases, 24 were females and 16 were males, of variable ages ranging between 25 and 55 years. The lesions were hyperchromatic in 29 cases $(72.5 \%)$, while patients with hypochromatic lesions were 11 cases $(27.5 \%)$. No patients were observed to have a combination of both. Also, results in Table 1 clearly indicat that the peak-age specific prevalence of PV was recorded higher among female patients, 25-30 years old.

\section{Microbiological studies}

In this study out of 40 cases; 80 isolates were collected and identified on the basis of their morphological characters and Gram stain reaction. Out of 80 isolates; 68 isolates $(85 \%)$ were pre- identified as Malassezia spp. and 12 $(15 \%)$ as Gram positive cocci. It was found that all Malassezia spp. isolates had the ability to grow on mDixon's agar at $32^{\circ} \mathrm{C}$ and can assimilate all Tweens and also split esculin after 2-3 days. In addition, they were tested for pigmentation ability. Seven M. furfur strains (isolates no. 5, $12,17,25,30,35$ and 39) produced a diffusible brown pigment, whereas others failed to produce pigment on mDixon medium. The production of a brown pigment by $M$. furfur strains which started after 36-48h was completed by day 7 after incubation. On the other hand bacterial isolates have undergone specific identification tests for $S$. aureus using standard methods. Finally four bacterial isolates (no. 2, 3, 7 and 11) were identified as $S$.aureus as they were $\beta$-haemolysis; coagulase and catalase positive.

TABLE 1. Frequency of Pityriasis versicolor (PV) with groups of different ages and sexes.

\begin{tabular}{lccc}
\hline Age/year & Females no. $(\%)$ & Males no. $(\%)$ & Total no. $(\%)$ \\
\hline $25-30$ & $11(27.5)$ & $2(5.0)$ & $13(32.5)$ \\
$31-39$ & $10(25.0)$ & $6(15.0)$ & $16(40)$ \\
$>40$ & $3(7.50)$ & $8(20.0)$ & $11(27.5)$ \\
Total & $24(60)$ & $16(40)$ & $40(100)$ \\
\hline
\end{tabular}




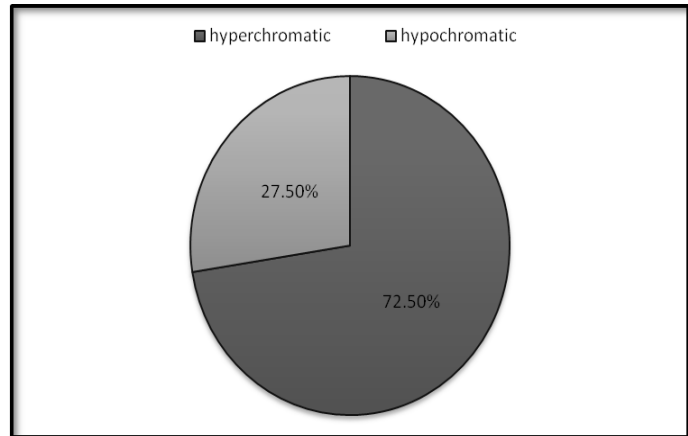

Fig. 1. Percentages of cases occurrences.

Results presented in Table 2 reveal that all of the applied EOs affect the tested pathogens with diameter of inhibition zone ranged from $8-24 \mathrm{~mm}$. EOs of clove, rosemary, eucalyptus and cinnamon have moderate effect, while tea tree oil has the most potent activity compared to the standard antimicrobial agents. All the tested strains examined in this study were sensitive to HAMS extracellular antimicrobial metabolites that are seemed to be constitutive expressed in non- stimulated condition of cultures. This was demonstrated by inhibition zone ranged in (12-19mm) formed around wells punched into solid microbial culture loaded with metabolitescontained medium collected from HAM culture. On the contrary to that, not effect has been noticed with IHAMS on any of the tested pathogens. Also, it was noted that microbial solid cultures layered with HAM tissue showed inhibition zone ranged from 10 to $16 \mathrm{~mm}$, meanwhile, cultures layered with IHAM tissue did not affect the tested strains (Table 2).

Table 2 elucidate that TTO and HAMS were the most effective antimicrobial agents against the tested strains. So, the effect of TTO or/and HAMS was quantitatively assessed by determining the MICs and (MFCs or MBCs) as given in Table 3 . The results clearly indicate that TTO was potent than HAMS with MICs ranged from $20-80 \mu 1 / \mathrm{ml}^{-1}$ which are lower than those recorded in the case of treatment with HAMS (50 to $100 \mu \mathrm{l} / \mathrm{ml}^{-1}$ ). However, in combination treatment of TTO \& HAMS, the MICs were in the range of $5-17.5 \mu \mathrm{l} / \mathrm{ml}^{-1}$ for the tested strains.

Table 4 shows that the combination of TTO with HAMS significantly reduced the MICs values of both compounds $(\mathrm{P}<0.05)$, this combination exhibits a remarkable synergistic activity which is reflected by changes in the MICs values of the tested isolates (FIC index for synergism ranged from 0.3 to 0.48 ).

\section{Release of cellular material that absorbs at $260 \mathrm{~nm}$}

Pathogens with the lowest FICI (M. furfur 25 and $S$. aureus 3) were chosen for studying the mechanism of antimicrobial action of TTO \& HAMS. The results indicated that a higher exposure time led to a higher cell leakage of cellular materials (Fig. 2). However, no changes in the absorbance of untreated cells (control) of tested strains were observed during the time intervals. At 60 and $120 \mathrm{~min}$ of treatment, a significant increase in ODs of the treated microbial culture filtrates was observed (Fig. 2a and $b$ ). This directly confirms the leakage of the material absorbing at $260 \mathrm{~nm}$ from the microbial cells treated with TTO and HAMS.

\section{Potassium ion efflux}

In this study, treatment of microbial cells with TTO, HAMS and TTO \& HAMS at their MIC induced a major efflux of intracellular $\mathrm{K}^{+}$ ions, following a sturdy loss along the specified intervals (Fig. 3a and b). However, no $\mathrm{K}^{+}$ion efflux was observed in control cells of the tested microbial pathogens during this experiment.

Scanning electron microscopic analysis (SEM)

Morphological alterations may take place on the cell surface of microbial pathogens when treated with antimicrobial agents. Hence, a SEM analysis was carried out to further visualize the effect of TTO \& HAMS on the morphological and surface characteristics of $M$. furfur 25 and $S$. aureus 3 cells as compared to the control group (Fig. 4, 5). Micrographs of M. furfur 25 (Fig. 4a) show the cells with typical morphology; grapeslike spherical spores with repetitive budding daughter cell and numerous filaments. While Fig. $4 \mathrm{~b}$ shows the effect of treatment with TTO \& HAMS at MIC, where some cells suffered from enlargement with slightly disappearance of filaments and disintegration of the components of other cells was observed. Also, SEM images demonstrat that untreated cells of $S$. aureus 3 have unique shapes (spherical shaped) with typical smooth- walled cocci arranged in an organized manner (Fig. 5a). In contrast, the incubation of tested strain with TTO \& HAMS at MIC for $18 \mathrm{~h}$ led to morphology changes such as elongation of some cells with rigid cell walls and cell destruction compared to the non treated cells (Fig. 5b). 


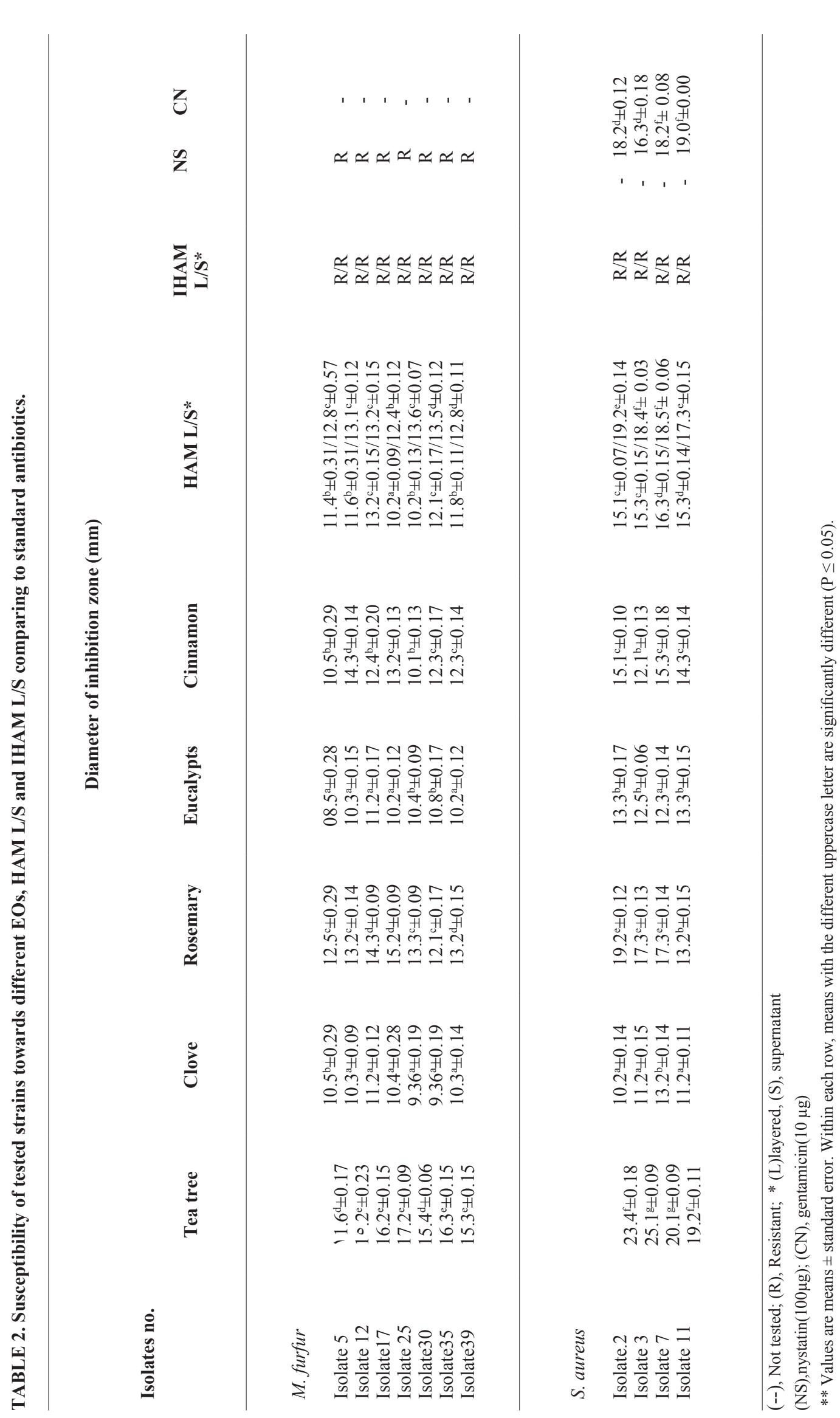

Egypt. J. Rad. Sci. Applic. 31, No.1 (2018) 
TABLE 3. Determination of MIC and (MFC\&MBC) values of TTO, HAMS and their combination against the tested strains.

\begin{tabular}{|c|c|c|c|c|c|c|}
\hline \multirow{2}{*}{ Tested strains } & \multicolumn{2}{|c|}{ TTO $(\mu \mathrm{l} / \mathrm{ml}$ medium $)$} & \multicolumn{2}{|c|}{ HAMS $(\mu \mathrm{l} / \mathrm{ml}$ medium $)$} & \multicolumn{2}{|c|}{$\begin{array}{c}\text { TTO \&HAMS }(\mu \mathrm{l} / \mathrm{ml} \\
\text { medium) }\end{array}$} \\
\hline & MIC & MFC & MIC & MFC & MIC & MFC \\
\hline \multicolumn{7}{|l|}{ M. furfur } \\
\hline Isolate no. 5 & 50 & 75 & 80 & 100 & 12.5 & 25.0 \\
\hline Isolate no. 12 & 50 & 75 & 75 & 75 & 12.5 & 25.0 \\
\hline Isolate no. 17 & 75 & 100 & 100 & 100 & 17.5 & 37.5 \\
\hline Isolate no. 25 & 75 & 75 & 100 & 120 & 12.5 & 25.0 \\
\hline Isolate no. 30 & 80 & 80 & 80 & 100 & 17.5 & 37.5 \\
\hline Isolate no.35 & 60 & 80 & 100 & 100 & 15.0 & 25.0 \\
\hline Isolate no. 39 & 50 & 80 & 80 & 80 & 15.0 & 25.0 \\
\hline S. aureus & MIC & MBC & MIC & MBC & MIC & MBC \\
\hline Isolate no.2 & 25 & 25 & 50 & 50 & 7.5 & 12.5 \\
\hline Isolate no.3 & 25 & 25 & 50 & 75 & 5.0 & 12.5 \\
\hline Isolate no.7 & 20 & 25 & 75 & 80 & 7.5 & 15.0 \\
\hline Isolate no.11 & 25 & 25 & 50 & 75 & 7.5 & 10.0 \\
\hline
\end{tabular}

TABLE 4. Fractional inhibitory concentration (FIC) values for the combination between TTO and HAMS against the tested strains.

\begin{tabular}{|c|c|c|c|c|}
\hline Tested Strains & FIC (TTO) & FIC (HAM) & FIC Index & Effect \\
\hline \multicolumn{5}{|l|}{ M. furfur } \\
\hline Isolate no. 5 & 0.25 & 0.16 & 0.41 & Synergism \\
\hline Isolate no. 12 & 0.25 & 0.17 & 0.42 & Synergism \\
\hline Isolate no. 17 & 0.23 & 0.18 & 0.41 & Synergism \\
\hline Isolate no. 25 & 0.17 & 0.13 & 0.30 & Synergism \\
\hline Isolate no. 30 & 0.22 & 0.22 & 0.44 & Synergism \\
\hline Isolate no. 35 & 0.25 & 0.15 & 0.40 & Synergism \\
\hline Isolate no. 39 & 0.30 & 0.19 & 0.49 & Synergism \\
\hline \multicolumn{5}{|l|}{ S. aureus } \\
\hline Isolate no.2 & 0.30 & 0.15 & 0.45 & Synergism \\
\hline Isolate no.3 & 0.20 & 0.10 & 0.30 & Synergism \\
\hline Isolate no.7 & 0.38 & 0.10 & 0.48 & Synergism \\
\hline Isolate no.11 & 0.30 & 0.15 & 0.45 & Synergism \\
\hline
\end{tabular}

FICI: fractional inhibitory concentrations index were calculated according to Yadav et al. (2013) and classified as follows: synergistic if FIC $\leq 0.5$, additive if FIC $>0.5$ and $\leq 1.0$, in different if FIC $>1.0$ and $\leq 2.0$, and antagonistic if FIC $>2.0$. 


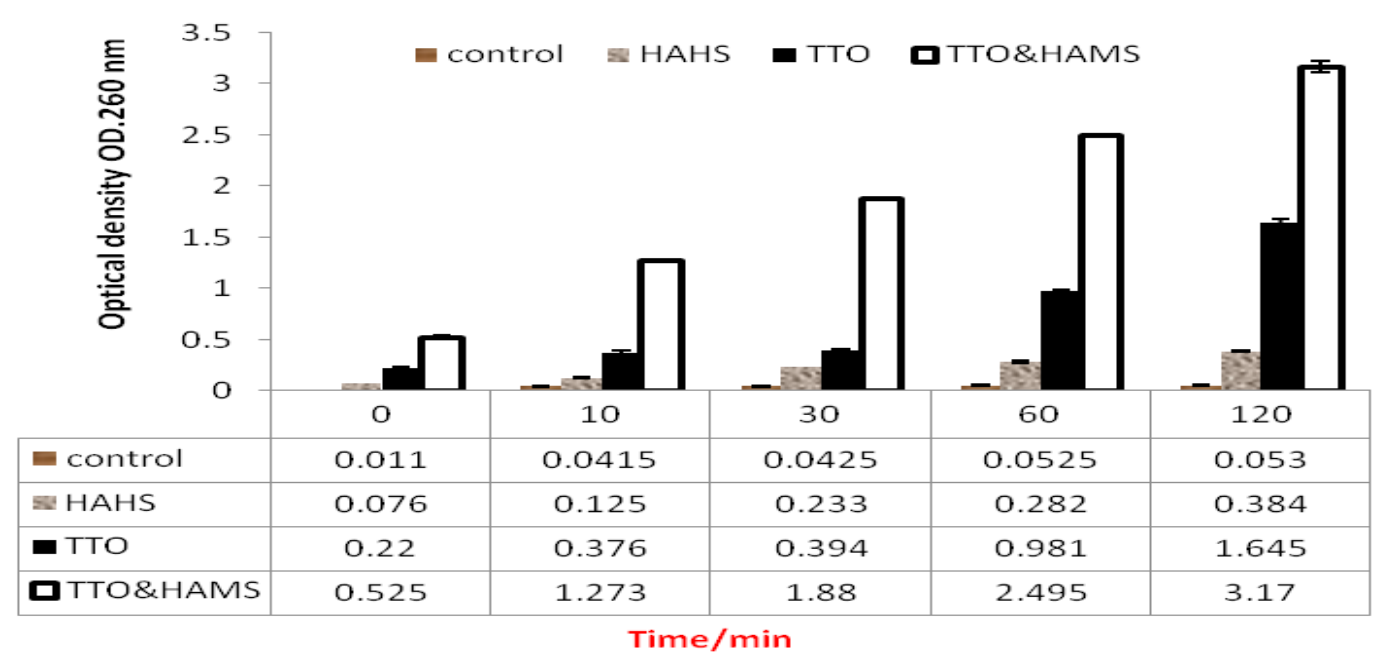

Fig. 2a. UV-Vis spectra of cell damage induced by TTO and HAMS against M. fufur 25. (Values are the mean \pm standard deviation, error bars represent standard deviation).

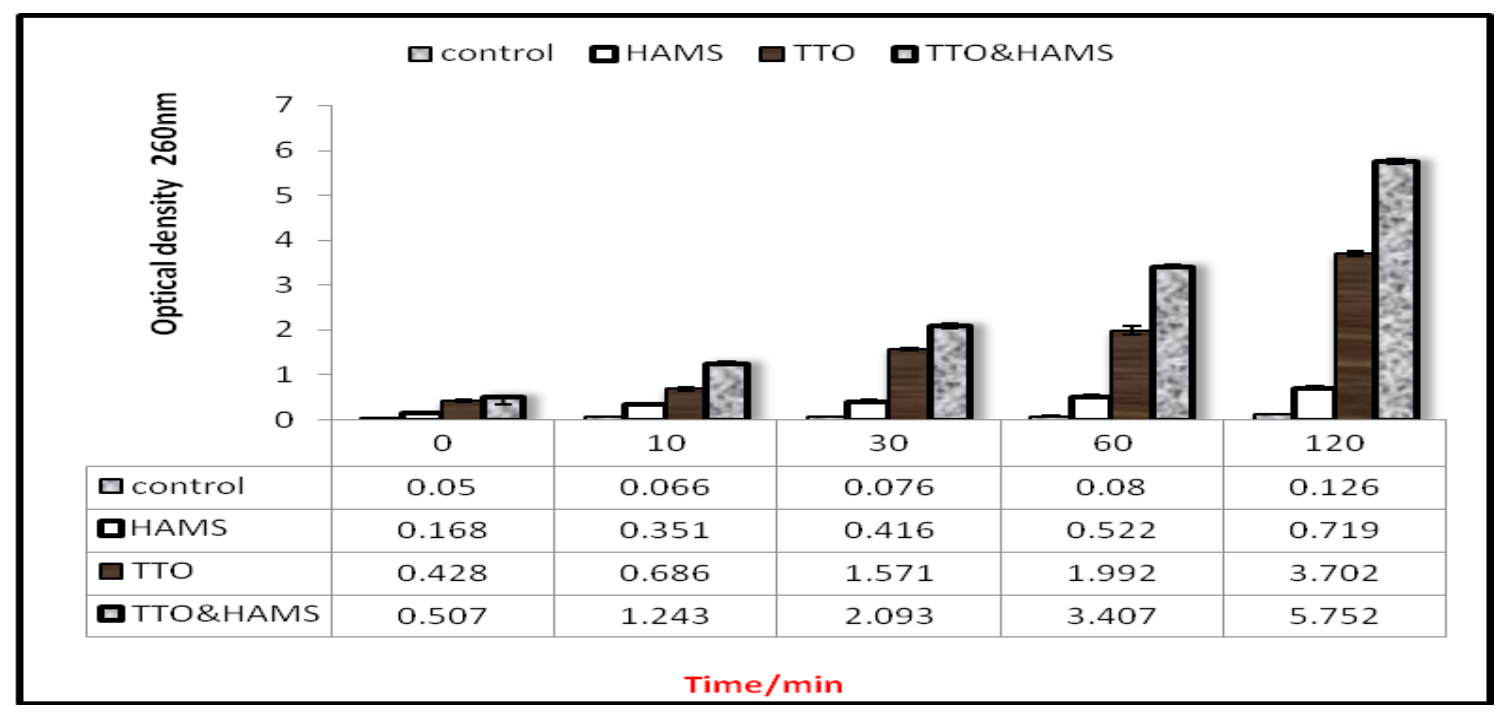

Fig. 2b. UV-Vis spectra of cell damage induced by TTO and HAMS against $S$. aureus 3. (Values are the mean \pm standard deviation, error bars represent standard deviation).

\section{Discussion}

Malassezia furfur and Staphylococcus aureus are considered normal microflora of human skin. Under certain conditions, both exogenous and endogenous can transform to a pathogenic form; these organisms play an important role in several diseases including PV (Bajpai et al., 2014). Results of the present study clearly demonstrate that the peak-age specific prevalence of PV was recorded among female patients; this is in agreement with
Kyriakis et al. (2006). Whereas prevalence of PV was higher among male patients $>40$ years old. As for the gender, the results indicate more prevalence in women $(60 \%)$ than in men $(40 \%)$. This is also confirmed by Tarazooie et al. (2004) who reported that the incidence of this infection is higher in women, which may be due to extra attention of women to beauty and skin hygiene, while Kordbacheh et al. (2004) found that, $60 \%$ of their tested cases were males. Generally, occurrence of Malassezia is verified in both sexes. 


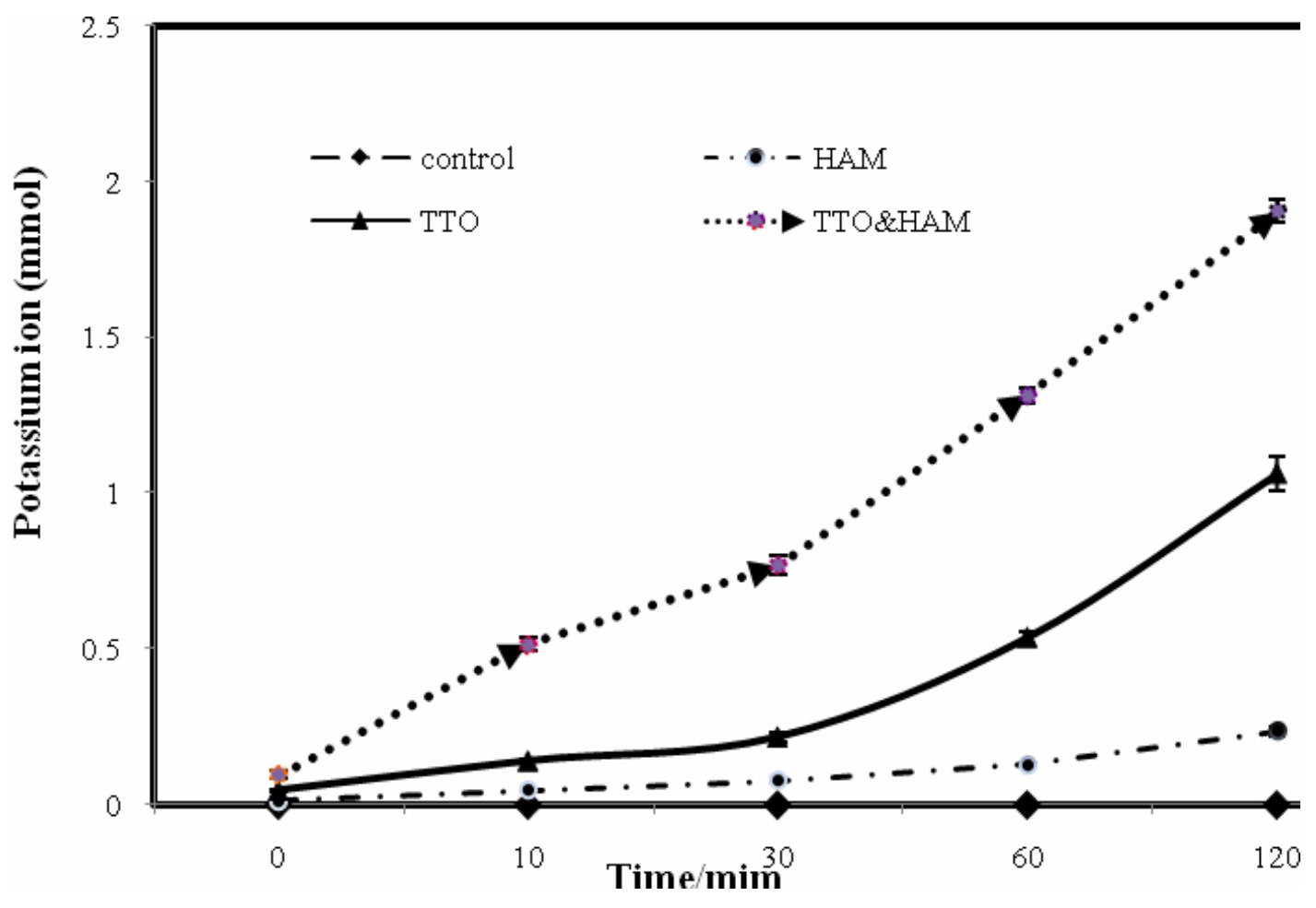

Fig. 3a. Effect of TTO or/and HAMS at MICs on the leakage of potassium ions from M. furfur 25 at different time intervals. (Results represent the mean of three replicates, error bars represent standard deviation).

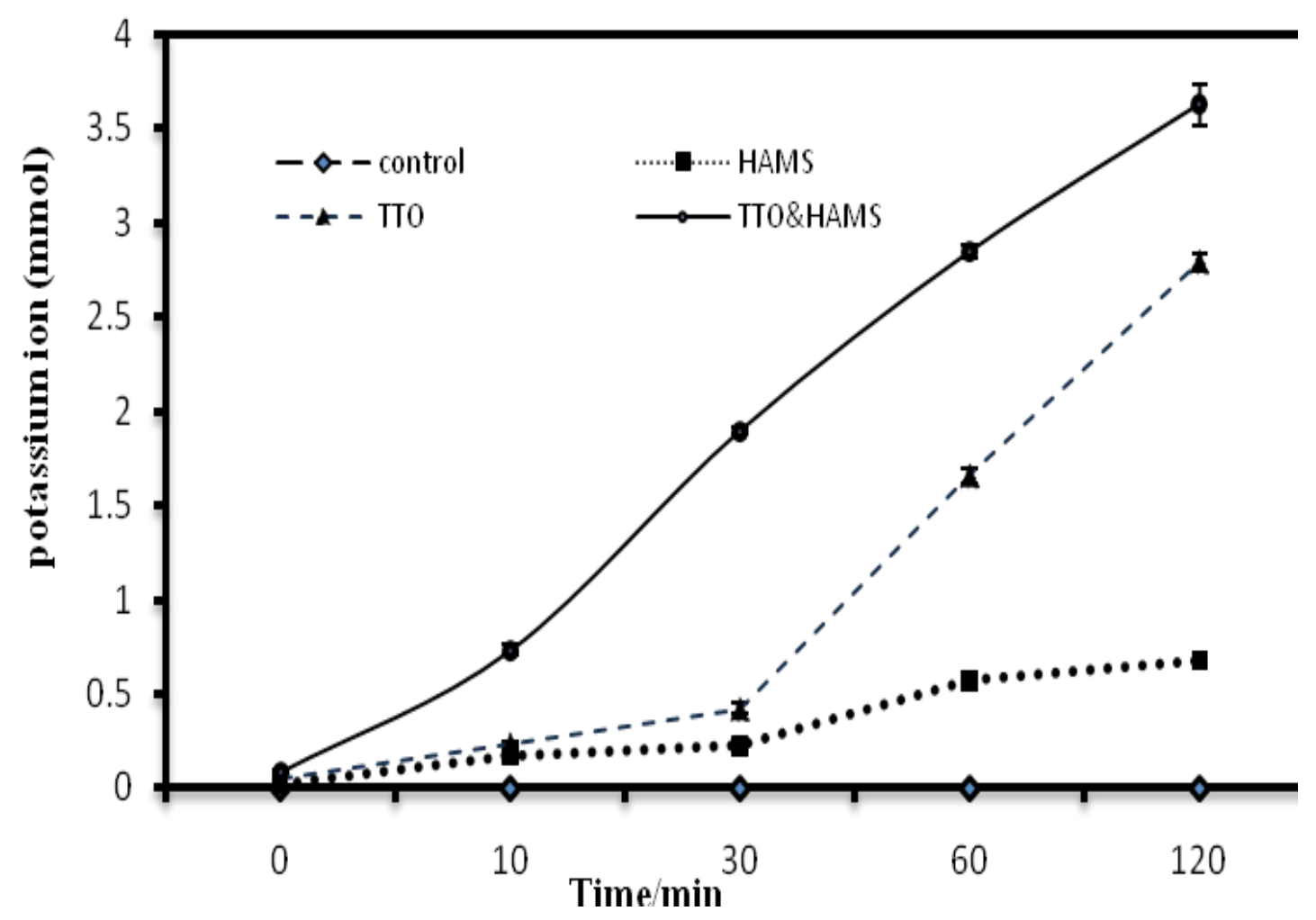

Fig. 3b. Effect of TTO or/and HAMS at MICs on the leakage of potassium ions from S. aureus 3 at different time intervals. (Results represent the mean of three replicates, error bars represent standard deviation). 
a

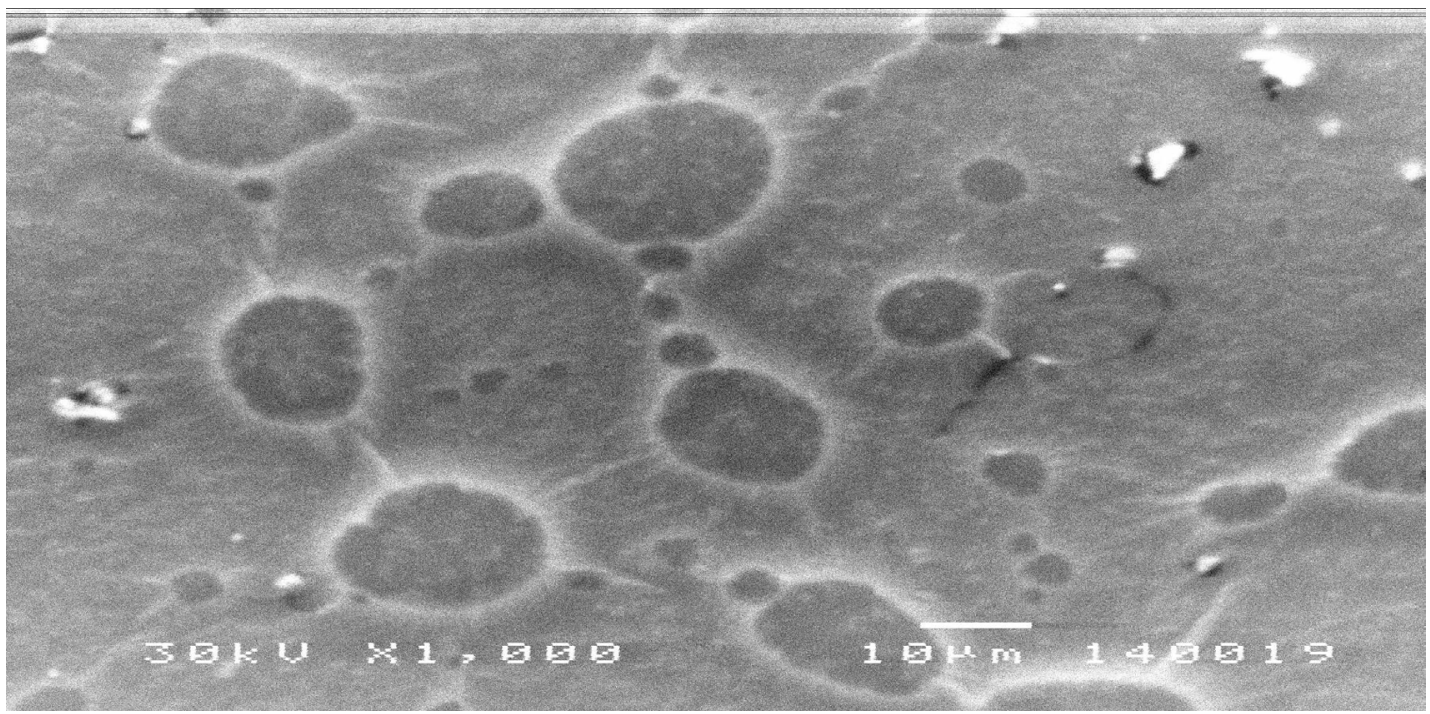

b

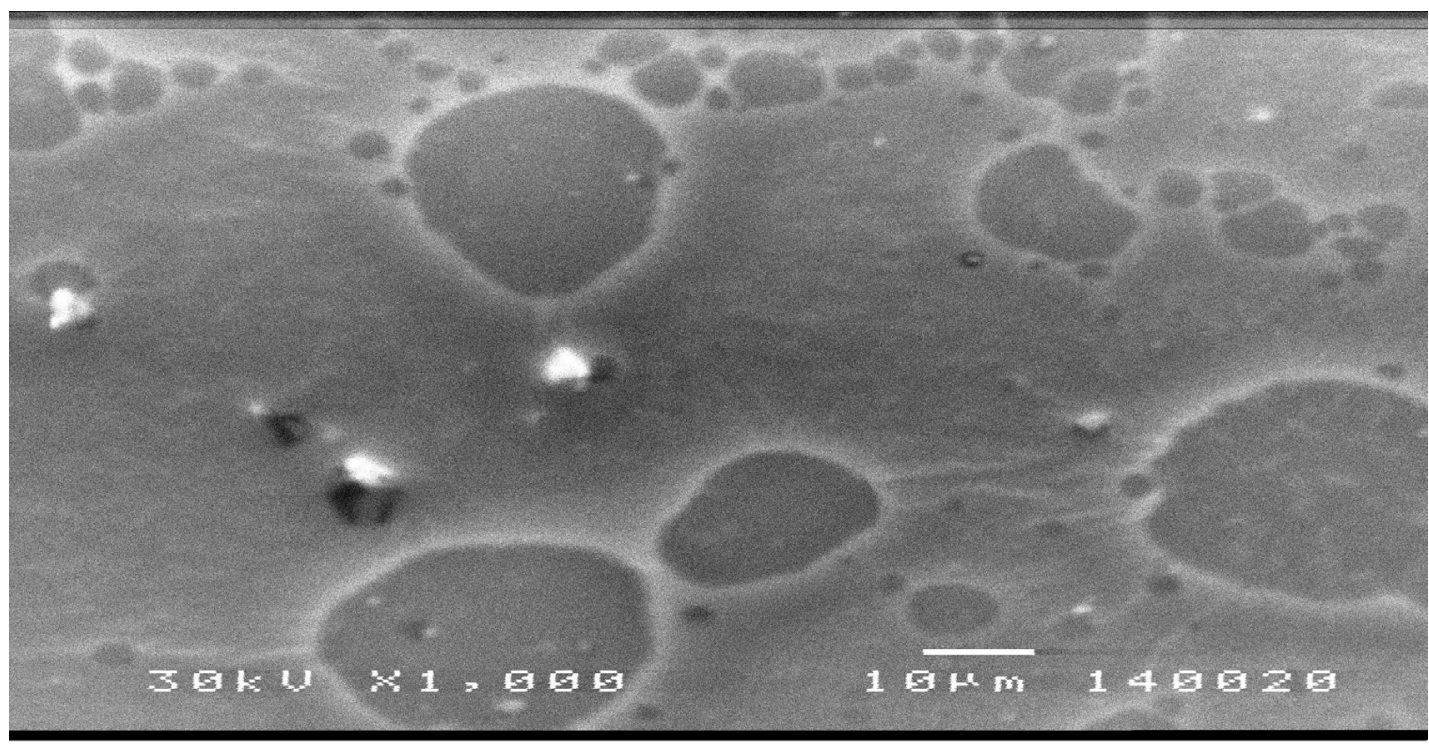

Fig. 4. Scanning electron micrographs of M. furfur, (a) untreated cells, (b) treated with combination of TTO \& HAMS at MIC.

The antimicrobial activity of certain bioactive compounds from medicinal plants has attracted a lot of attention within the scientific community largely as a result of the growing problem of multidrug resistance among microorganisms. Based on these facts, the present study emphasizes the importance of EOs as an alternative antimalassezia and antistaphyolcoccal agents. Also, antimicrobial properties of HAM were well documented by Parthasarathy et al. (2014). In this study, different EOs, HAM and IHAM were screened for their potential activity against the isolated $M$. furfur and $S$.aureus. It was found that out of the tested oils, tea tree oil (TTO) had the most potent activity, whereas clove, rosemary, eucalyptus and cinnamon oils have moderate effects. In vitro Carson et al. (2006) verified the susceptibility of Malassezia species to TTO and the present study confirmed and extended these findings. A study conducted by Donnarumma et al. (2007), reported that AV119 which extracted from Avocado gratissima fruits inhibited the invasiveness of $M$. furfur to human keratinocytes. Also, Ramanuj et al. (2012) found that different plant extracts affected pathogens under their study including $M$. furfur, while Pooja et al. (2013) concluded that eucalyptus oil was inactive against $M$. furfur. 
a

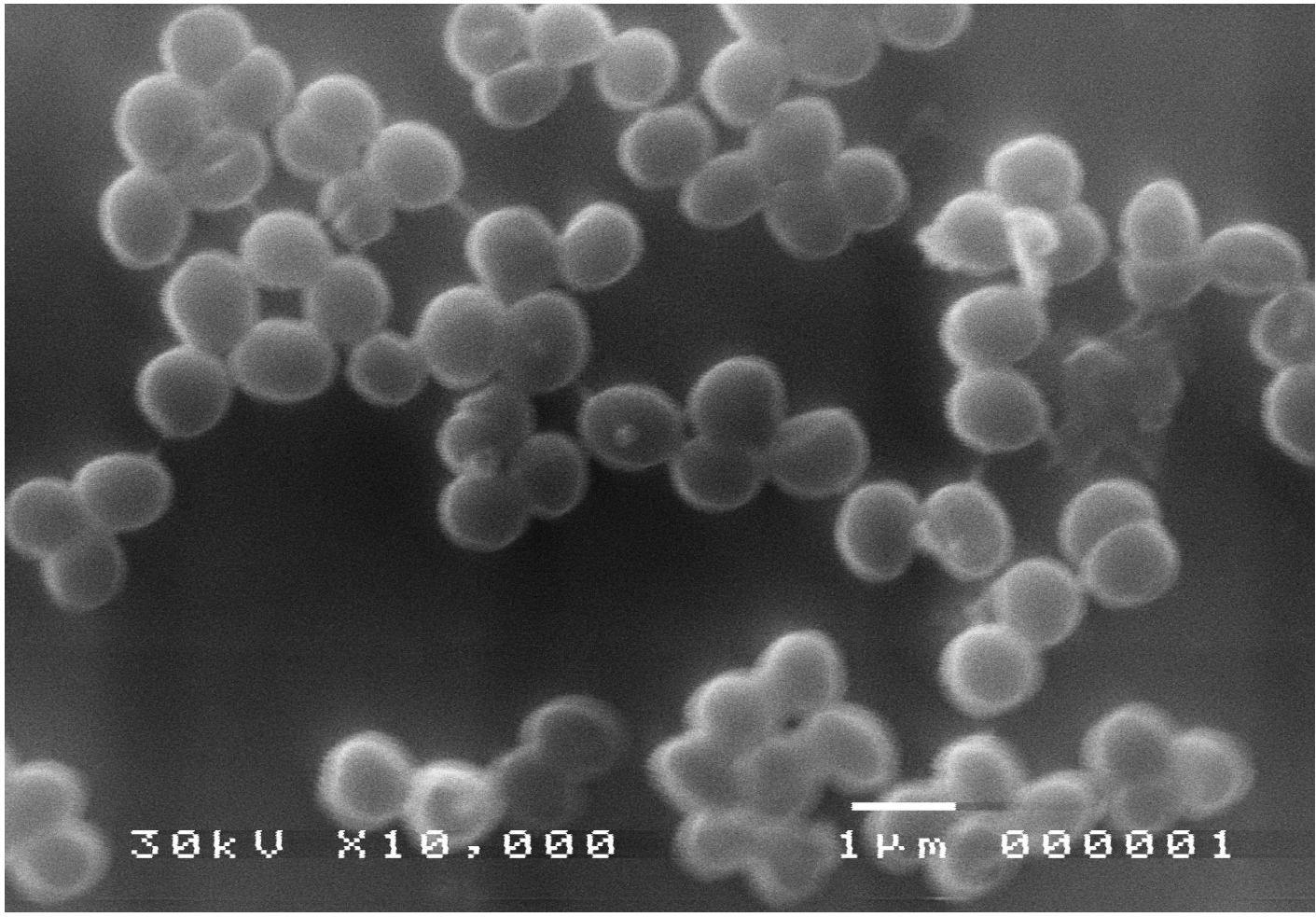

b
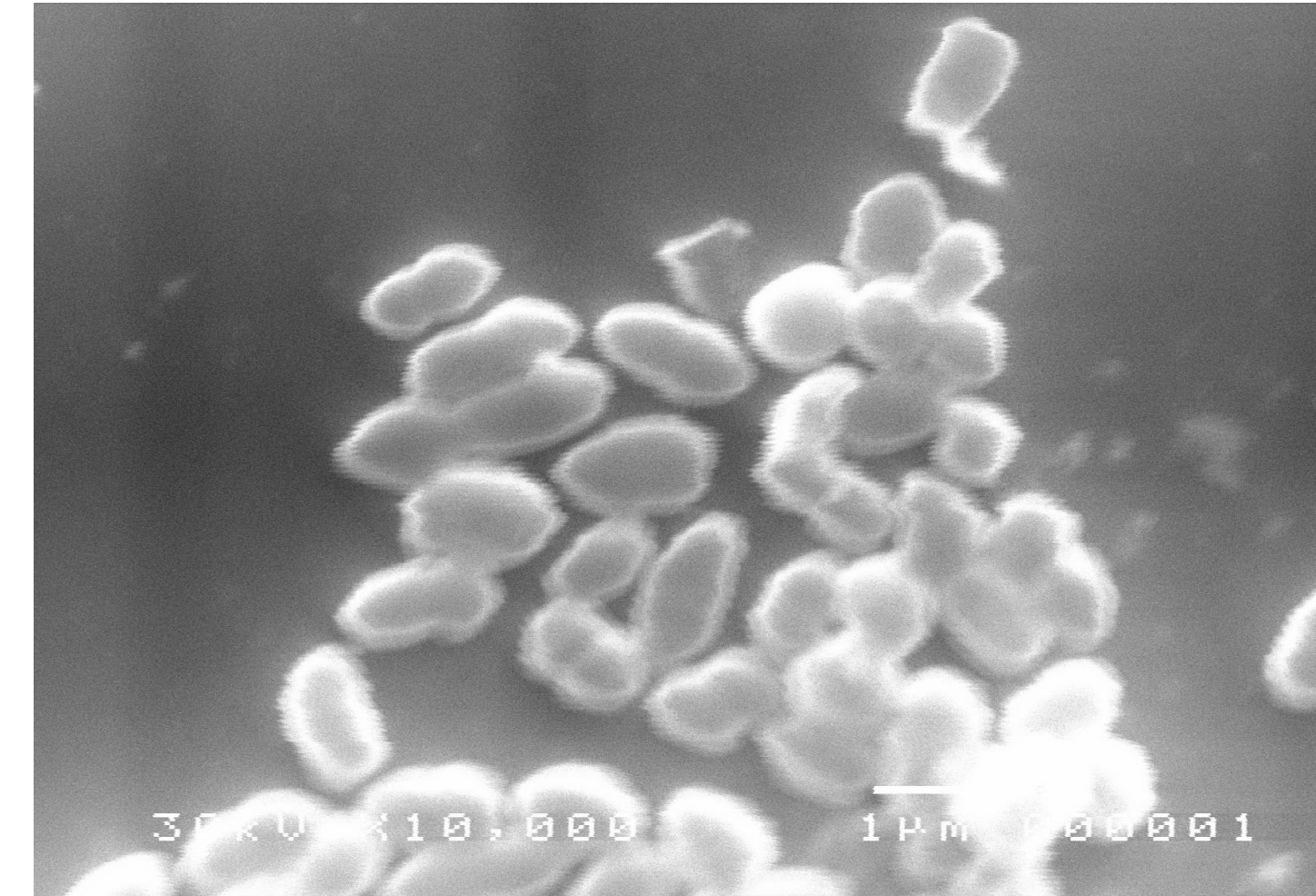

Fig. 5. Scanning electron micrographs of $S$. aureus 3, (a) untreated cells, (b) treated with combination of TTO \& HAMS at MIC. 
Tea-tree oil (TTO), the essential oil of Melaleuca alternifolia, has been suggested as a potential agent for MRSA decolonization, as it has been shown to be an effective broad-spectrum antimicrobial with good activity in vitro against a variety of bacteria including $M R S A$, that can be principally attributed to terpinen-4-ol (Puja, 2013).

Chao et al. (2008) reported that TTO contains over 100 components; many of which are antimicrobial in nature. Another possible advantage of this complexity is suggested by a study of the interaction of two components of TTO,1, 8-cineole and terpinene. While 1, 8-cineole exhibits little antimicrobial activity inherently, it has been shown toenhance the lethal action of terpinene. It is hypothesizedthat 1,8 -cineole helps permeabilize bacterial membranes, allowing the more active terpinene to enter and kill bacterial cells.

Nenoff et al. (1996) reported that TTO has displayed in vitro activity against $M$. mycetomatis and $M$. furfur, proving its potentialin treating eumycetoma, pityriasis, and seborrheic dermatitis, not only because of its antifungal activity, but also due to its ability to penetrate the skin.

All the tested strains examined in this study were sensitive to HAML/S, while IHAM cannot affect them. Antimicrobial activity of vital HAM was proved by Niknejad et al. (2008) and Chopra \& Thomas (2013), which is due to secretion of constitutive expression of low molecular weight antimicrobial peptides as definsins, which are considered as broad spectrum antibiotics, these released peptides led to killing wide range of microbial cells including Gram- positive and Gram- negative bacteria and $C$. albicans as a potential pathogenic fungus (Nemr et al., 2017). Also, many of clinical trails using amniotic membrane as a biological bandage were published for curing some of skin disorders and ulcers. This is due to several biological benefits revealed by amniotic membrane such as being a nonimmunogenic material, having antimicrobial activity and inducing cellular renewing and growth (Nemr et al., 2016).

In the current study, the data reveal that IHAM had no effect in vitro, this may be due to the tissue banking processes which affect the viability of cells that cause malfunction HAM secretions. This result was also confirmed by Nemr et al. (2016) who reported that, gamma irradiation of HAM at a dose of $25 \mathrm{kGy}$ affects the quality of the extracted RNA and causes completely degradation of RNA molecules. It is known that intact RNA only presented in metabolic active cells. This fact proved the importance of HAM viability to utilize its own healthy secretome concerning genes encoding antimicrobial peptides, cytokines and growth factors to accelerate the healthy growth of target cells (Yatim et al., 2013).

Combined drug treatment is recommended as a strategy to control antimicrobial resistance (Fischbach, 2011), the effect of TTO or/and HAMS was quantitatively assessed by determining the MICs. Generally, the results clearly demonstrate that MICs of TTO \& HAMS in combination were lower than those recorded in the case of TTO or HAMS alone. The results presented in this study highlight the potentiality of TTO and HAMS for treatment of PV patients. Further work is presently underway to characterize the action mechanisms of these interesting compounds responsible for the synergistic activity against the tested isolates.

The leakage of cytoplasmic membrane was analysed by determining the release of cellular materials including nucleic acids, metabolites and ions, which were absorbedat $260 \mathrm{~nm}$ into the microbial suspensions. This strategy for determining the mechanism of antimicrobial action of TTO and HAMS was applied against pathogens with the lowest FICI (M. furfur 25 and $S$. aureus $3)$. The results indicate that increasing the time of exposure leads to an increase in leakage of cellular materials. However, nochanges in the absorbance of untreated cells (control) of tested strains were observed during the study.

The microbial cytoplasmic membrane provides a permeability barrier to the passage of small ions such as $\mathrm{H}^{+}, \mathrm{K}^{+}, \mathrm{Na}^{+}$and $\mathrm{Ca}^{2+}$, which are the most prevalent cations in the cytoplasm, facilitating cell membrane functions, charge balancing and protein synthesis, and maintaining proper enzyme activity that allows the cell to adapt to elevated osmolarity (Cox et al., 2001). This impermeability to small ions is maintained and even regulated by the structural and chemical composition of the membrane itself. The internal ionic environment of bacterial cells is generally potassium rich; therefore, increases in the leakage of $\mathrm{K}^{+}$ions indicate a disruption of this permeability barrier. So, the mechanism of antimicrobial action of TTO and HAMS against 
the tested pathogens was further confirmed using the assay for the release of $\mathrm{K}^{+}$ions from the treated cells of $M$. furfur 25 and S.aureus 3. In this study, treatment of microbial cells with TTO \& HAMS at their MIC induced a major efflux of intracellular $\mathrm{K}^{+}$ions. However, no $\mathrm{K}^{+}$ion efflux was observed in control cells of the tested strains. Leakage of intracellular material is ageneral phenomenon induced by many antimicrobial substances, which results in cell death

Cox et al. (2001) have demonstrated that TTO inhibits the growth of $S$. aureus and $E$. coli by altering cell permeability, increasing the leakage of intracellular $\mathrm{K}^{+}$ions and disturbing cell respiration. The essential oils pass through the cell wall and cytoplasmic membrane, which may disrupt the arrangement of dissimilar fatty acids, phospholipids bilayers, and polysaccharides molecules. All these mechanisms may be responsible for the coagulation of inner cellular components in the cytoplasm and break down of the bonds between the lipid and protein layers (Burt, 2004). The lipophilicity of essential oils enables them to preferentially partition from an aqueous phase into membrane structures of the fungi, resulting in membrane expansion, increased membrane fluidity and permeability, disturbance of membrane-embedded proteins, inhibition of respiration, disintegration of mitochondrial membranes, alteration of ion transport processes in fungi and leakage of ions and other cellular contents (Fadli et al., 2012 and Aleksic \& Knezevic, 2014).

Moreover, the SEM analysis was performed to investigate morphological alterations in the cell wall of the tested pathogens. The inhibitory effect of TTO \& HAMS was confirmed by severe morphological alterations on the cell wall of the tested strains, leading to enlargement, disruption and cell lysis. Carson et al. (2006) reported that treatment of $S$. aureus with TTO resulted in leakage of potassium ions and cellular materials that absorbed at $260-\mathrm{nm}$ and also produced morphological changes apparent under electron microscopy.

\section{Conclusion}

Results of the present investigation highlight the powerful effect of TTO, which acts synergistically with HAMS against $M$. furfur and $S$. aureus. SEM analysis reveal that these pathogens show case various types of cell deformation when treated with TTO \& HAMS at their MIC. These findings lead for future alternative treatment for PV skin disorders. Periodic use of such antimicrobial agents would conceivably prevent re-infection, which is the most common problem. Further in-vivo clinical trials and genetic studies will also be needed to elucidate the exact mechanism of action.

\section{Compliance with ethical standards}

Conflict of Interest: The authors declare no conflicts of interest.

Ethical approval: All procedures performed in studies involving human participants were in accordance with the ethical standards of the institutional and national research committee and with the 1964 Helsinki declaration and its later amendments or comparable ethical standards.

Informed consent: Informed consent was obtained from all individual participants included in the study.

\section{$\underline{\text { References }}$}

Aleksic, V. and Knezevic, P. (2014) Antimicrobial and antioxidative activity of extracts and essential oils of Myrtus communis L. Microbiological Research, 169(4), 240-254.

Bajpai, K.V., Sharma, A. and Baek, K.H. (2014) Antibacterial mode of action of the essential oil obtained from Chamaecyparis obtusa sawdust on the membrane integrity of selected foodborne pathogens. Food Technol. Biotechnol. 52(1), 109-118.

Boerlin, P., Kuhnert, P.,Hussy, D. and Schaellibaum, M. (2003) Methods for identification of Staphylococcus aureus isolates in cases of bovine mastitis. J. Clinic. Microbiol. 41(2), 767-771.

Burt, S. (2004) Essential oils: Their antibacterial properties and potential applications in foods: A review. International Journal of Food Microbiology, 94, 223-253.

Carson, C.F., Hammer, K.A. and Riley, T.V. (2006) Melaleuca alternifolia (Tea tree) Oil: A Review of antimicrobial and other medicinal properties. Clinical Microbiology Reviews, 19(1), 50-62.

Chao, S., Young, G., Oberg, C. and Nakaoka, K. (2008) Inhibition of methicillin-resistant Staphylococcus 
aureus (MRSA) by essential oils. Flavour and Fragrance Journal, 23, 444-449.

Chopra, A. and Thomas, B.S. (2013) Amniotic membrane: A novel material for regeneration and repaire. Biomim. Biomater. Tissue Eng. 18. 10.4172/1662-100x.1000106.

CLSI (Clinical and Laboratory Standards Institute) (2008) Performance standards for antimicrobial disk and dilution susceptibility tests for bacteria isolated from animals; Approved standard M31-A3, $3^{\text {rd }}$ ed. Wayne, PA, USA.

Cox, D.S., Mann, M.C., Markham, L.J., Gustafson, E.J., Warmington, R.J. and Wyllie, G.S. (2001) Determining the antimicrobial actions of Tea tree oil. Molecules, 6, 87-91.

Donnarumma, G., Buommino, E., Baroni, A., Auricchio, L., De Filippis, A., Cozza, V., Msika, P., Piccardi, N. and Tufano, A.M. (2007) Effects of AV119, a natural sugar from avocado, on Malassezia furfur invasiveness and on the expression of HBD-2 and cytokines in human keratinocytes. Experimental Dermatology, 16, 912-919.

Fadli, M., Saad, A., Sayadi, S., Chevalier, J., Mezriouia, N. E. and Pagèsc, J.M. et al (2012) Antibacterial activity of Thymus maroccanus and Thymus broussonetii essential oils against nosocomial infection-bacteria and their synergistic potential with antibiotics. Phytomedicine, 19, 464-471.

Feng, G.W. and Yu, L.M. (2014) Research progress of human amniotic membrane applications. Zhong Guo Sheng Wu Gong Cheng Za Zhi, 31(4), 930-4.

Fischbach, M.A. (2011) Combination therapies for combating antimicrobial resistance. Curr. Opin. Microbiol. 14, 519-523.doi:10.1016/j. mib.2011.08.003

Framil, V.M.S., Melhem, M.S.C., Szeszs, M.W., Cometa, E.S. and Zaitz, C. (2010) Pitryaisis versicolor circinata: Isolation of Malassezia sympodialis: Case report. An BrasDermatol. 85, 227-228.

Ghahfarokhi, S.M. and Abyaneh, R.M. (2004) Rapid identification of Malassezia furfur from other Malassezia Species: A major causative agent of Pityriasis versicolor. Iran. J. Med. Sci. 29(1), 36-39.

Guerra-Rosas, M.I., Morales-Castro, J., Cubero-
Marquez, M.A., Salvia-Trujillo, L. and MartínBelloso, O. (2017) Antimicrobial activity of nanoemulsions containing essential oils and high methoxyl pectin during long-term storage. Food Control, 77, 131-138.

Gupta, A.K., Kohli, Y., Faergemann, J. and Summerbell, R.C. (2001) Epidemiology of Malassezia yeasts associated with Pityriasis versicolor in Ontario, Canada. Med. Mycol. 39, 199-206.

Haidaris, C.G. and Brownlow, E.J. (2001) "Working Safely with Biological Samples, in Molecular Biology Problem Solver: A Laboratory Guide". A. S. Gerstein (Ed.), John Wiley \& Sons, Inc., New York, USA. doi: 10.1002/0471223905.ch5.

Helsinki (2013) WORLD MEDICAL ASSOCIATION (WMA) Declaration of Helsinki - Ethical Principles for Medical Research Involving Human Subjects $19^{\text {th }}$ October.

Holt, J.G., Krieg, N.R., Sneath, P.H., Safety, J.T. and Williams, S.T. (1993) "Bergey's Manual of Determinative Bacteriology". Williams, K. and Wilkins, O. (Ed.), Baltimore, USA.

Isobe, K., Inoue, N., Takamatsu, Y., Kamada, K. and Wakao, N. (2006) Production of catalase by fungi growing at low $\mathrm{pH}$ and high temperature. J. Biosci. Bioeng. 101(1), 73-76. doi:10.1263/jbb.101.73. PMID 16503295.

Kordbacheh, P., Zaini, F., Tarazooie, B., Zomorodian, K., Saadat, F., Zeraati, H., Hallaji, Z. and Rezaie, S. (2004) Study of the distribution of Malassezia species in patients with Pityriasis versicolor and healthy individuals in Tehran, Iran. BMC.Dermatology, 4-5

Kurlenda, J. and Grinholc, M. (2012) Alternative therapies in Staphylococcus aureus diseases. Acta Biochim. Pol. 59(2), 171-184.

Kyriakis, K.P., Terzoudi, S., Palamaras, I., Pagana, G., Michailides, C. and Emmanuelides, S. (2006) Pityriasis versicolor prevalence by age and gender. Mycoses, 49(6), 517-8.

Mayser, P., Haze, P., Papavassilis, C., Pickel, M., Gruender, K. and Gueho, E. (1997) Differentiation of Malassezia species: Selectivity of cremophor EL, castor oil and ricinoleic acid for M. furfur. Br. J. Dermatol. 137(2), 208-13. 
Nemr, W., Bashandy, A.S., Araby, E. and Khamis, O. (2016) Biological activity alterations of human amniotic membrane pre and post irradiation tissue banking. Pak. J. Biol. Sci. 19(7), 289-298.

Nemr, W., Bashandy, A.S., Araby, E. and Khamis, O. (2017) Molecular displaying of differential immuno- response to various infections of amniotic epithelia.. Am. J. Reprod. Immunol. 00:e12662. https://doi.org/10.1111/aji.12662.

Nenoff, P., Haustein, U.F. and Brandt, W. (1996) Antifungal activity of the essential oil of Melaleuca alternifolia (tea tree oil) against pathogenic fungi in vitro. Skin Pharmacol. 9(6), 388-94.

Niknejad, H., Peirovi1, H., Jorjani, M., Ahmadiani, A., Ghanavi, J. and Seifalian, A.M. (2008) Properties of the amniotic membrane for potential use in tissue engineering. European Cells and Materials, 15, 88-99.

Park, H.J., Lee, Y.W., Choe, Y.B. and Ahn, K.J. (2012) Skin characteristica in patients with Pityraisis versicolor using non- invasive method MAPA5, Annals of Dermatology, 24(4), 444-52.

Parthasarathy, M., Sasikala, R., Gunasekaran, P. and Raga, J. (2014) Antimicrobial activity of human amniotic and chorionic membranes. Journal of Academia and IndustrialResearch (JAIR),2(10), 545-547.

Pooja, A., Arun, N. and Maninder, K. (2013) Screening of plant essential oils for antifungal activity against Malassezia furfur. International Journal of Pharmacy and Pharmaceutical Sciences, ISSN0975-1491, 5(2).

Puja, K. (2013) Antimicrobial properties of tea tree oil. International Journal of Bioinformatics and Biological Science, 1(1), 71-77.
Ramanuj, K., Bachani, P. and Kothari, V. (2012) In vitro antimicrobial activity of certain plant products/seed extracts against multidrug resistant Propionibacterium acnes, Malassezia furfur and aflatoxin producing Aspergillus flavus. Research in Pharmacy, 2(3), 22-31.

Rios-Yuil, M.J. (2016) Pityriasis versicolor: Clinical spectrum and diagnosis. Curr Fungal Infect. Rep. 10, 121-125.

Sugita, T., Takashima, M., Kodama, M., Tsuboi,R. and Nishikawa, A. (2003) Description of a new yeast species, Malassezia Japonica and its detection in patients with atopic dermatitis and healthy subjects. J. Clin. Microbiol. 41, 4695-9.

Tarazooie, B., Kordbacheh, P., Zaini, F., Zomorodian, K., Saadat, F., Zeraati, H., Hallaji, Z. and Rezaie, S. (2004) Study of the distribution of Malassezia species in patients with Pityriasis versicolor and healthy individuals in Tehran. Iran. BMC. Dermatology, 4(5),1-6.

Yadav, M.K., Park, S.W., Chae, S.W., Song, J.J. and Kim, H.C. (2013). Antimicrobial activities of Eugenia caryophyllata extract and its major chemical constituent eugenol against Streptococcus pneumoniae. Acta Pathologica,Microbiologica et Immunologica Scandinavica, 121(12), 1198-1206.

Yatim, R.M., Kannan, T.P., Ab Hamid, S.S. and Shamsudin, S.H. (2013) Effects of different processing methods of human amniotic membrane on the quality of extracted RNA. Arch. Orofac. Sci. $8(2), 47-53$. 


\section{النثاط المضاد لبعض الزيوت الطيارة والغثاء الأمنيوسى الآدمي على مالاسبزيا فيرفز واستافيلوكوكس أوريس المعزولة من مرضى التينيا الملونة}

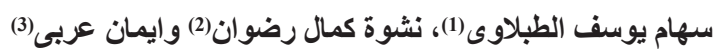

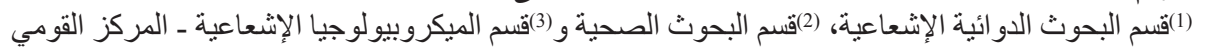

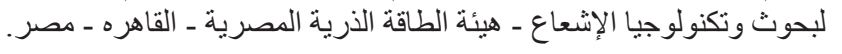

\footnotetext{
تعد أجناس فطر المالاسيزيا وبعض أجناس البكتيريا الموجودة على الجلد من الميكروبات الإنتهازية حيث يمكنها

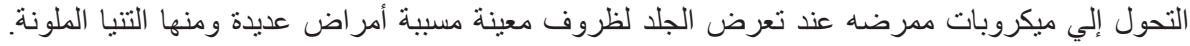

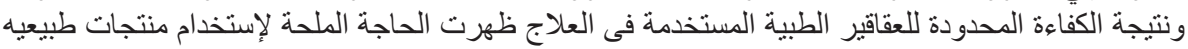
مختلفة لما لها من قدرة عاليه على مقاومة الميكروبات.

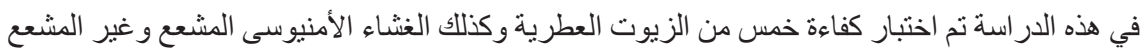

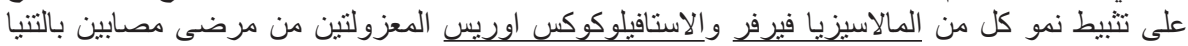

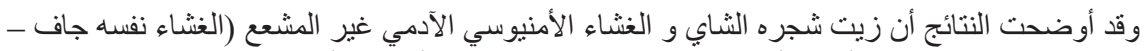

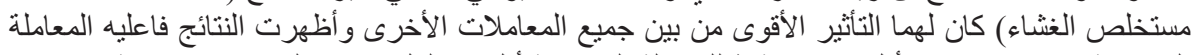

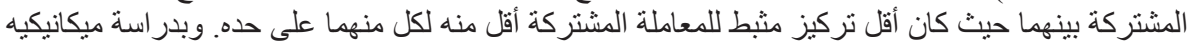

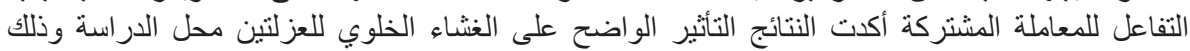

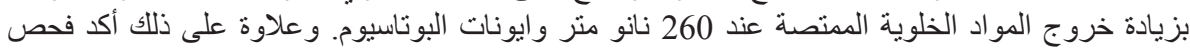

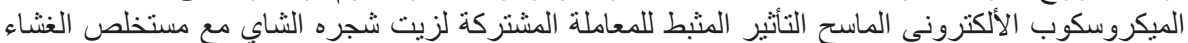
الأمنيوسي الآدمي حيث أظهرت الصور تغير اتئ شكلية مع تمزق للجدار الخلوي للخلايا المعاملة.

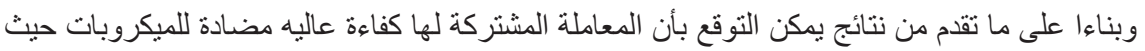

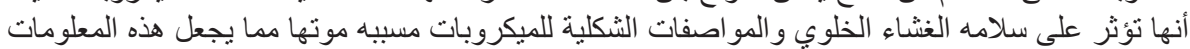

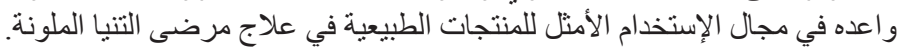

